\title{
Singulares aportaciones
} desde la restauración para el conocimiento de la escultura ligera novohispana. El caso del Señor de la Ascensión (Cristo Resucitado) de la Catedral de Tlalnepantla, México, y su adscripción al Taller de Cortés

Unique Contributions from Restoration to the Knowledge of Novohispano Religious Sculpture. The Case of the Señor de la Ascensión (Cristo Resucitado) of the Cathedral of Tlalnepantla, Mexico, and its Affiliation to the Taller de Cortés

Pablo F. Amador Marrero

Investigador del Instituto de Investigaciones Estéticas (IIE),

Universidad Nacional Autónoma de México (UNAM), México agueretf@hotmail.com

\section{Resumen}

Como resultado de los diferentes estudios realizados en paralelo a los procesos de restauración de la escultura ligera con caña de maíz del Señor de la Ascensión de la Catedral de Tlalnepantla, México, han quedado de manifiesto tanto su técnica constructiva como su materialidad. Efecto de todo ello, pero también de la necesaria incorporación de los análisis propios de la historia del arte, la presente INVESTIGACIÓN plantea que se trata del primer ejemplo que no corresponde con la representación de Cristo en la cruz, que puede adscribirse al Taller de Cortés, prolífico obrador de la Ciudad de México, activo en el último tercio del siglo XVI.

\section{Palabras clave}

escultura virreinal; materialidad; caña de maíz; madera ligera; Catedral de Tlalnepantla; México

\section{Abstract}

As a result of the different studies carried out in parallel to the restoration processes of the lightweight corn stalk sculpture of the Señor de la Ascensión of the Cathedral of Tlalnepantla, Mexico, 
both their constructive technique and materiality have been made apparent. As a result of this, but also of the need to incorporate analysis specific to art history, this RESEARCH poses that this is the first example that does not correspond to the representation of Christ on the cross, which can be ascribed to the Taller de Cortés, a prolific space in Mexico City active in the last third of the $16^{\text {th }}$ century.

\section{Keywords}

Viceregal sculpture; materiality; corn stalk; light wood; Cathedral of Tlalnepantla; Mexico

os famosos cristos de caña de maíz son uno de los campos que mayor avance han experimentado en el sustancial impulso a los estudios sobre escultura virreinal novohispana en los últimos decenios. Las diferentes investigaciones que se han centrado en el tema, desde el ámbito académico, ofrecen una imprescindible puesta en orden de la bibliografía como resultado del oportuno trabajo historiográfico, lo que ha dejado de manifiesto múltiples problemáticas; en especial, la ausencia de revisiones reflexivas, indispensables para generar nuevos cuestionamientos (Ávila 2010-2011). Esa falta ha lastrado el desarrollo en el conocimiento y valoración de esta técnica que, considero, es una aportación de la plástica mexicana virreinal a la historia de la escultura policromada hispana.

En otros casos, que ven superada la problemática indicada, se han establecido ya nuevos parámetros, en cuanto a su relación con la escultura ligera europea del momento, y a la diferenciación de centros productores (Michoacán y la Ciudad de México), formulación de adscripciones de múltiples piezas a diferentes obradores y cronologías, su materialidad, sistemas de construcción y evolución en el siglo XVI hasta su declive, avanzada la centuria siguiente (Amador 2012). Lo anterior ha repercutido, a su vez, en nuevos progresos que, con ejemplos puntuales, insisten en lo material y formal (Quintero 2013; Valverde y Martín 2017: 72-78).

Ahora bien, aunque los señalados avances han deparado importantes y diferentes lecturas respecto de la escultura que nos ocupa, también es necesario apuntar que la "tradición" mantiene un peso significativo, como se refleja en otros textos, asimismo contemporáneos, en los que se mantiene que:

the devotional images of maize stalk that have been preserved in Mexico are a clear expression of religious syncretism, something that should not be simply interpreted as the result of the union of a pre-Hispanic manufacturing technique with Christian symbols. Beyond that, it must be understood as the amalgamation of different religious beliefs as a consequence of a particular historical process and the cultural dynamics [Brito 2014: 125].
Al respecto, sólo gracias a los avances que se publiquen y a su revisión crítica llegaremos a un necesario diálogo que desemboque en el imprescindible consenso y establezca definitivamente el lugar y la percepción de esa singular tipología escultórica novohispana en la historia del arte de México.

En esa tesitura, nuestra aportación en este caso es plantear, una vez más en relación con lo apuntado por Cesare Brandi, cómo a partir de los procesos de intervención, de conservación y, más aún cuando se trata de restauración —entiéndase siempre en el ámbito profesional—, es el momento metodológico ideal para hacerle nuevas preguntas a las obras y, con ello, sumar conocimiento alrededor de éstas (Brandi 1995: 15). Con esa idea siempre en el punto de mira, propongo estudiar desde múltiples formas de aproximación una pieza todavía hace poco desconocida para la bibliografía: la imagen ligera hueca y con caña de maíz que representa a Cristo Resucitado, perteneciente a la Catedral de Tlalnepantla, Estado de México. De entrada, mi propósito es situarla como obra de referencia en un ámbito en el que prevalecen las representaciones de Cristo crucificado $y$, a lo sumo, algunas efigies de santos, como los conocidos conjuntos procesionales de Santiago Matamoros (Museo Nacional del Virreinato (MNV), Tepotzotlán, y Santa María Chiconautla, Ecatepec (ambos en el Estado de México), o de representaciones marianas como la conservada en el MNV, todas de sobra conocidas. Partiendo de su análisis formal y de su relación con códigos identificativos, a modo de señas particulares establecidas para algunos obradores propuestos, se busca su posible filiación con uno de esos talleres que, según la documentación que estudié, permanecieron activos durante el último tercio del siglo XVI (Amador 2012: 226-258). A partir de dicho vínculo, gracias a la restauración, ahondaré en la tecnología y manufactura de la obra, contrastando de nuevo los resultados. La finalidad es traer al escenario de la escultura ligera virreinal un importante y nuevo actor - fuera de los habituales en su iconografía-, que abre ese espectro en los que se desarrollaron los talleres de la Ciudad de México en la época señalada, y atender a la versatilidad que, con la finalidad de cumplir con una demanda cada vez mayor y variada en cuanto a las representaciones, registraron sus obradores (Figura 1).

\section{La escultura: desde lo histórico y lo formal}

Mi interés por esta pieza tiene su primer momento cuando, a raíz de una conferencia que impartí en la Catedral de Tlalnepantla, centrada en el Cristo de las Misericordias que preside su retablo mayor, reparé en ella y desde ese momento establecí algunos pareceres con base en sus formas, planteando una hipotética adscripción a un mismo obrador, cuestión que aquí pretendo resolver. ${ }^{1}$

\footnotetext{
${ }^{1}$ La conferencia se tituló "El Cristo de la Catedral (Señor de las Misericordias). Una imagen de referencia para el arte de México en Tlal-
} 


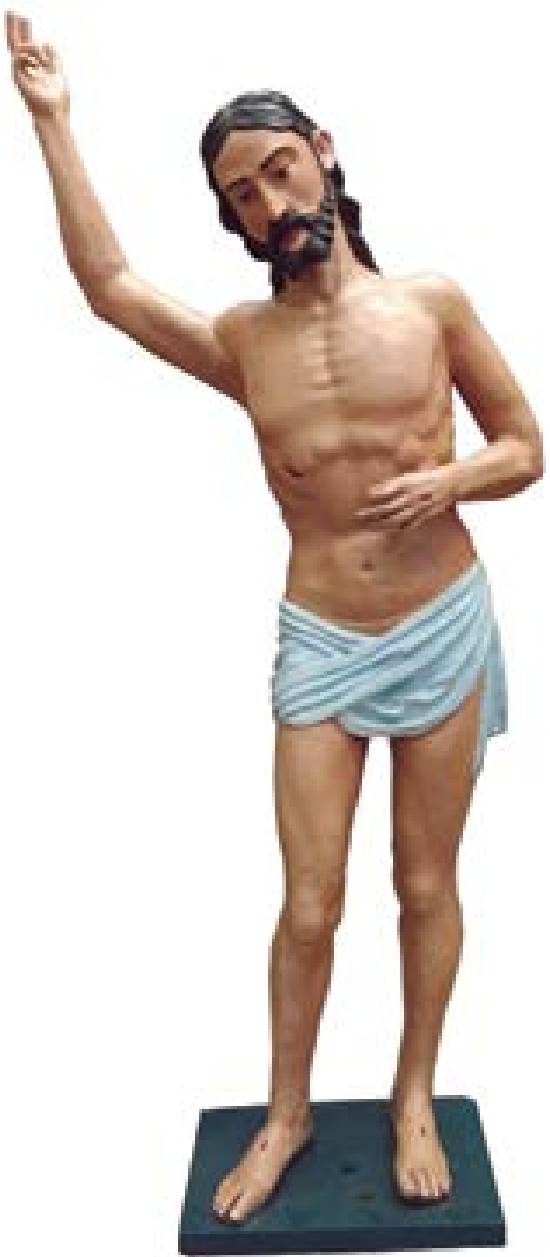

FIGURA 1. Señor de la Ascensión (Cristo Resucitado) antes de la restauración, Catedral de Tlalnepantla. Escultura ligera con caña de maíz, Taller de Cortés, finales del siglo XVI (Fotografía: Claudia Alejandra Garza Villegas, 2016).

Posteriormente, con motivo de la exposición Al canto de las quimeras. Luis Lagarto y la fábrica de la cantoría de la Catedral de Puebla, 1600-1611, la imagen fue solicitada para incluirla en la sección "Luis Lagarto en el arte de su tiempo", en la que hacía un elocuente pendant con una de las miniaturas del citado iluminador que comparten similar tema y postura, acorde con los postulados iconográficos vigentes en las décadas de transición entre los siglos XVI Y XVII (Figura 2).

En contraprestación al préstamo para su exhibición, el Museo Amparo de Puebla, organizador de la exposición, junto con la Diócesis de Tlalnepantla y su catedral, patrocinó la necesaria restauración que, por su profesionalidad y demostrada solvencia en obras de igual materialidad,

nepantla", dictada el 14 de mayo de 2014 en la propia Catedral de Tlalnepantla, Estado de México.

${ }^{2}$ Ya había analizado puntualmente el tema de la iconografía de Cristo Resucitado en la escultura ligera y sus débitos en mi texto doctoral respecto de una pieza conservada en el exconvento de Tzintzuntzan, Michoacán (Amador 2012: 443-445).

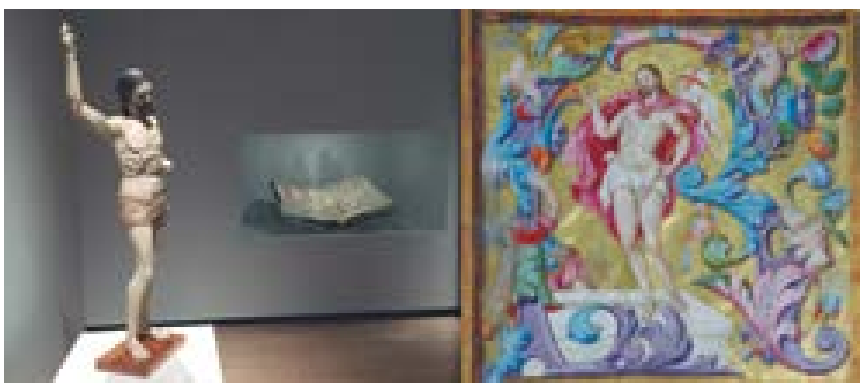

FIGURA 2. Señor de la Ascensión e iluminación de la Resurrección de Cristo por Luis Lagarto, hacia 1600-1611. Exposición Al canto de las Quimeras", Museo Amparo, Puebla (Fotografía: Pablo F. Amador Marrero, 2016).

recayó en los expertos Claudia Alejandra Garza Villegas como titular, junto a Ramón Avendaño Esquivel y Naitzá Santiago. ${ }^{3}$ Por mi parte, con antelación a dichos trabajos, ya había sometido la escultura a diferentes estudios radiológicos que imperiosamente fueron de referencia para dicha actuación. Esos análisis ofrecieron, tal y como desarrollaré, una parte fundamental del conocimiento material y constructivo de la efigie, aspectos imprescindibles para su posterior cotejo con el obrador al que había propuesto su adscripción.

La escultura objeto del presente trabajo se encuentra actualmente en una de las capillas del claustro del antiguo convento franciscano de Tlalnepantla, desde 1964 sede catedralicia y del obispado del mismo nombre. Si bien, como decía, había pasado totalmente inadvertida para la historia del arte - como la mayor parte del patrimonio mueble del templo-, en la amplia bibliografía consultada no he encontrado reporte alguno o noticias al respecto. Gracias a las loables labores de catalogación e inventario del archivo catedralicio que en los últimos años ha venido realizando la historiadora Rebeca López Mora (FES Acatlán de la UNAM), sabemos que en 1786 se le denominaba Señor de la Ascensión y formaba parte del Altar del Santo Entierro, ubicado en la nave del templo:

La imagen en su nicho con vidrios (finos) romanos, colchón de bramante, sábana de Bretaña y sobrecama de media tela encarnada, tres almohadillas. Una imagen del Señor de la Ascensión con capa de seda, vieja, resplandor de madera dorada. Cinco lienzos grandes y dos chicos de buena pintura bien tratados, banco y sotabanco de madera pintado de encarnado; frontal de bastidor viejo. Una cruz de madera ordinaria de una cuarta; un atril viejo plateado [Archivo Histórico de la Catedral de Tlalnepantla 1786: 11]. ${ }^{4}$

\footnotetext{
${ }^{3}$ La intervención se realizó en los meses anteriores a la inauguración de la exposición, el 15 de diciembre de 2016, llevada a cabo en dependencias de la propia catedral y con la pertinente supervisión del INAH Estado de México.

${ }^{4}$ A lo indicado en el inventario se añade: "Sobrecama de terciopelo morado con galón de oro en poder del mayordomo del dicho Señor: sin sotabanco". La transcripción y adaptación de las referencias es mía.
} 
En lo concerniente a dicha referencia como Señor de la Ascensión, es interesante entenderla en su contexto, ya que ante el titular del altar, el Cristo Difunto, establecía una sencilla lectura de cumplida victoria sobre la muerte, que mantiene cuando los Domingos de Resurrección se la coloca en el retablo mayor, ocupado el resto del año por la efigie similar del Cristo de las Misericordias, estableciéndose con un efectivo juego de cambios iconográficos pero con un mismo o similar referente (Figura 3). Esta iconografía también la había visto en otra obra ligera, en esa ocasión de Michoacán —como señalaba, el otro centro productor novohispano de escultura ligera-, del que ya he adelantado algunos aspectos (Amador 2012: 443-445). Ahora bien, entre ambas existe primeramente una sustancial diferencia en cuanto a tecnología, ya que en el caso del antiguo obispado de Valladolid, debido a su mal estado de conservación, me fue fácil evidenciar una naturaleza ligera pero maciza, mientras que en el que nos ocupa su resonancia me puso en aviso de que se trataba de una pieza en gran parte hueca, lo cual constituye una de las características más notables de ambos centros productores, aunque ello no debe considerarse como generalidad.

Tomando en cuenta los antecedentes señalados, mis primeros pasos se encaminaron lógicamente al estudio formal de la obra, en el que destacan varios aspectos. Por principio, ha de valorarse el cuidado puesto en su trazado general, donde se evidencia una preocupación por las proporciones y correspondencias anatómicas. A no ser por cierta dificultad en la disposición de los brazos respecto del torso, a lo que luego volveré, puedo señalar un trabajo que pone en evidencia tanto el conocimiento de las formas como su efectiva traslación al volumen.

Para no demorarme en esta parte, referiré algunos puntos en el trazo de la pieza que nos llevan directamente a su relación con el obrador al que lo adscribo. De entrada, en la cabeza, tanto en su forma general como el trabajo de la barba o el pequeño mechón que discurre delante de la oreja se repiten patrones de manera constante. También es significativo el tratamiento del tórax, con las costillas muy marcadas y la particularidad de destacar la zona de la punta del esternón (apéndice xifoides). Pero es sin duda el diseño del paño de perizonium, o paño de pudor, donde se establece una de las inequívocas señas de identidad del taller. Éste, como en la gran mayoría de las obras que se han relacionado con su obrador, es pequeño, con multitud de plegados sencillos de crestas suaves, entre los que destacan el que se forma frontalmente y discurre con una marcada diagonal desde la zona superior izquierda hasta el punto opuesto en la derecha. En cuanto a su ornamentación, pese a los burdos repintes de material reciente, desde el inicio mi experiencia en la aplicación de la radiología en escultura me puso al tanto de su pervivencia

Quiero agradecer a Claudia Alejandra Garza Villegas su generosidad al compartirme estos interesantes datos inéditos.

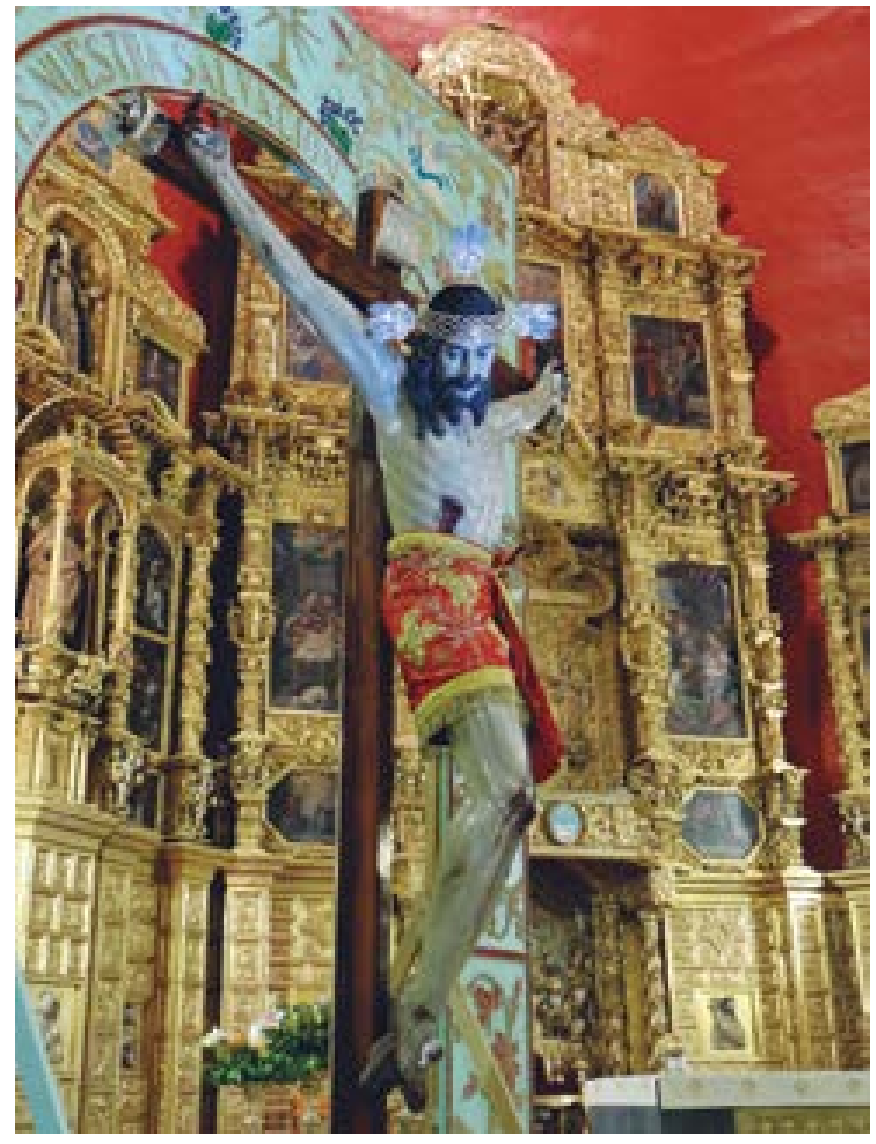

FIGURA 3. Señor de la Misericordias, Catedral de Tlalnepantla. Escultura ligera con caña de maíz, Taller de Cortés, finales del siglo XVI (Fotografía: Pablo F. Amador Marrero, 2015).

y también de su diseño. Éste es, como luego se recuperó, un sencillo esgrafiado sobre temple blanco a base de franjas (Figura 4).

Las anteriores especificaciones, repetidas en su mayoría en el señalado Cristo de la Misericordias, también nos llevan lógicamente a plantear que, además de recurrir los comitentes - ya fueran los propios frailes u otros devotos- a un mismo taller, el de Cortés, quizá obedezca al mismo encargo, lo que complementaría para su momento el discurso pasionista. Estos argumentos aún no se han atendido suficientemente en el ámbito de la escultura de la primera centuria virreinal, menos aún, en su condición de pieza de claras connotaciones procesionales, lo que nos ilustra, fuera de las habituales visiones del martirio, cómo la celebración de la gloria de la Resurrección contaba en algunos lugares con aparatos escénicos que debían ser presididos por imágenes efectivas.

Otro de los resultados de la evaluación formal de esta obra de Tlalnepantla reside en la contemporaneidad de su modelo. Salvando las distancias, es fácil establecer cómo dicho trazado, con infinidad de fuentes de referencias en grabados y pinturas tanto europeas - entre ellas españolas - como algunas novohispanas, está en perfecta sintonía con las representaciones coetáneas que se realizaban en el devoto mundo hispánico. Así, un ejemplo 


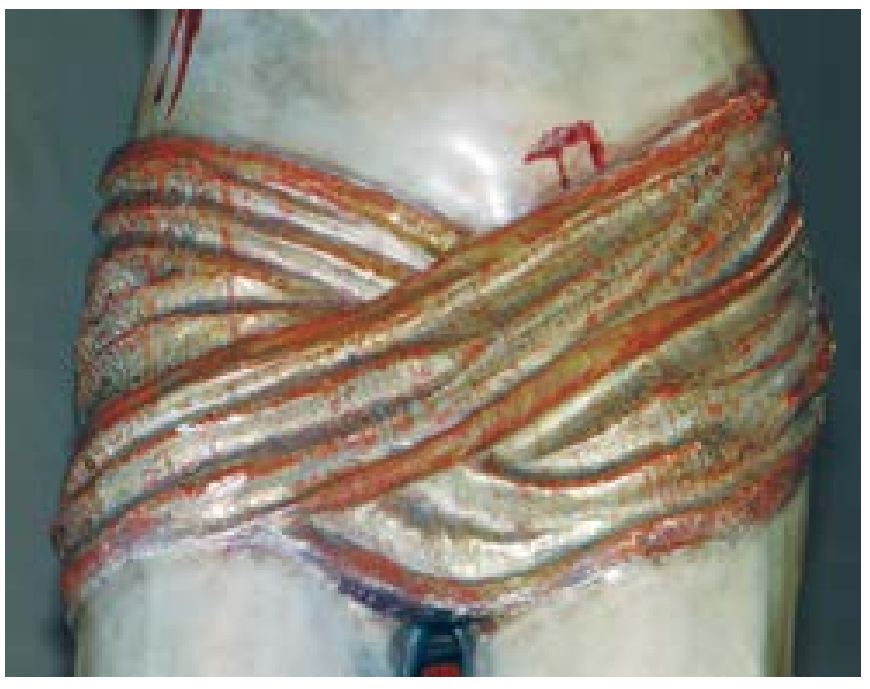

FIGURA 4. Paño de pureza del Señor de las Misericordias, Catedral de Tlalnepantla. Escultura ligera con caña de maíz, Taller de Cortés, finales del siglo XVI (Fotografía: Pablo F. Amador Marrero, 2015).

sencillo consiste en comprobar cómo no está tan alejado formalmente de obras como el famoso Cristo Resucitado de la iglesia sevillana de la Magdalena, entre cuyas corporaciones penitenciales, la de la Quinta Angustia, venera el famoso simulacro realizado por el célebre escultor Jerónimo Hernández, con quien contrataron la pieza en mayo de $1582 .{ }^{5}$ En efecto, ambas efigies, indistintamente de un hipotético vínculo más próximo del que planteo, son resultado de un similar panorama devocional y obedecen a los postulados estéticos vigentes, acordes con un momento en el que se potencia la representación escultórica de esta iconografía; argumento que necesariamente ha de tenerse en cuenta para comprender el particular encargo de la pieza mexicana y lo señalado de su uso en la Pascua de Resurrección.

\section{Proceso constructivo y materialidad comparados}

Tras comprobar las evidentes relaciones formales entre la pieza de Tlalnepantla y el señalado obrador de Cortés, esas correspondencias me llevaron necesariamente a la pertinente pregunta de si se repiten en lo relativo al sistema constructivo. Al respecto, conozco a detalle la tecnología y la materialidad a la que se recurrió para los crucificados adscritos a ese obrador, pero también a su centro de producción, todo gracias a referencias históricas y estudios científicos modernos resultado tanto de algunos análisis como de diversas intervenciones. Sobre esa base, también busqué en la pieza de Tlalnepantla su similitud $\mathrm{o}$, en su defecto, las posibles diferencias, con el fin de plantear cómo por el cambio iconográfico sus hacedores

\footnotetext{
${ }^{5}$ Esta imagen es citada por Francisco Pacheco (1991: 108). Respecto del escultor y su relación con la cofradía del Dulce Nombre que la encargó, véase Roda Peña (2016: 251-253).
}

recurrían a diferentes fórmulas constructivas y materiales. Para dar respuesta me apoyé primero en la radiología con la toma de algunas placas de rayos $\mathrm{X}$ convencionales, $\mathrm{Y}$ posteriormente con la realización de una tomografía computarizada completa. ${ }^{6}$ Conjugué los resultados de su evaluación con los aportados por otros métodos de análisis, en estos casos, de sus materiales — realizados según avanzó la restauración-, por lo que se cuenta con una pormenorizada documentación técnica de la materialidad y del proceso mismo de manufactura, a la que ahora doy lugar siguiendo el proceso natural de su ejecución.

Para dar inicio al Señor de la Ascensión de Tlalnepantla, su obrador debió contar con una estructura primigenia a modo de matriz o molde, hecha con algún material que requería cierta resistencia para facilitar su constante manipulación, por lo que probablemente era de madera. Ahora bien, en algunos casos se ha identificado su ejecución en barro modelado, como lo tenemos constatado en la imagen indiana en papelón representando a Santa Ana que forma parte del acervo del Museo Franz Mayer, Ciudad de México (Amador 2012: 127-131). En esta obra, quizá por la particularidad de la iconografía —no tan frecuente en contraposición al alto número de piezas inventariadas que representan a Cristo crucificado-, parte de la matriz quedó en el interior de los brazos, lo que no he encontrado en ninguna otra ocasión, con la salvedad de pequeños fragmentos de adobe (barro con restos vegetales) en el Cristo de Telde, Gran Canaria (Amador 2002: 112), lo que - ahora propongo- no justifica el principio general de su manufactura.

Ese uso de moldes debió ocuparse en la imagen que nos compete para la ejecución del alma de papelón que documenté en dos partes gracias a los resultados de la tomografía: la cabeza y el cuerpo desde el cuello, sin contar ambos brazos, hasta la zona inferior de las rodillas. Así, sobre esos moldes, que debieron ser muy simples en sus formas, se construyeron dichas almas a partir de la superposición de pliegos encolados, de forma semejante a la conocida técnica del papel maché. Una vez secas las estructuras, se retiraron de los moldes cortándolos por el perímetro longitudinal lateral - lo que se intuye por la separación de algunos pliegos en el interior, como se logra ver, aunque con cierta dificultad, en la tomografía-, para luego completarlas y unirlas con refuerzos en el mismo material. Un elocuente ejemplo histórico que refiere ese proceder en la realización de imágenes ligeras similares de la segunda mitad del siglo XVI está en la meticulosa descripción del proceso constructivo del famoso Señor de Santa Teresa, anteriormente Cristo de Ixmiquilpan, en el estado de Hidalgo. En el momento de su evaluación con motivo de la escrupulosa restauración que se le ejecutó

\footnotetext{
${ }^{6}$ Para ello recurrí a la reconocida empresa mexicana Laico, empleando su modelo i325, que destaca por su gran calidad y alta eficiencia, además de sus favorables condiciones al prescindir del uso de placas y químicos contaminantes.
} 
tras quedar gravemente deteriorado a causa de un sismo a mediados del siglo XVII, en el que le cayó encima la cúpula de su templo en el Centro Histórico de la Ciudad de México, su laborioso restaurador apuntó:

Toda ella está formada sobre una horma hueca, que parece construida en molde desde el cuello y una pequeña parte de los hombros, hasta la mitad de las piernas, y cuya horma está hecha en dos mitades, una que forma todo el frente, o parte delantera, y la otra, la posterior, adheridas o ensambladas ambas por medio de unas lienzas de la misma materia que dicha horma [...] La cabeza está igualmente hueca y formada por dos mitades de arriba abajo [Velasco 1858: 153] (Figura 5).

En efecto, ese mismo proceder también se ha descrito para otras piezas relacionadas con los obradores de la Ciudad de México, entre los que se encuentran diferentes ejemplos que adscribí al taller de Cortés. Uno de los casos más conocidos sería el del Cristo de Churubusco, Museo de las Intervenciones, Ciudad de México, del que en su momento el destacado restaurador Rolando Araujo me mostró las placas de la tomografía que se le hizo en los años noventa del siglo pasado. ${ }^{7}$ Otro sería el Cristo de la capilla anexa a la hoy Catedral de Tlaxcala, imagen de referencia por ser de la que parte la generación del taller y, por lo tanto, la que le da su nombre (Amador 2002: 5657, con base en Dubois 2001: 205-215). Respecto del último, gracias a la pérdida de la lazada del paño de pureza quedó abierto el orificio en el que debió fijarse el perno para su sujeción, lo que permitió un primer escrutinio de su interior con la aplicación de videoscopia portátil, lo que corroboró el procedimiento y los materiales descritos. En cuanto a la materialidad de esta horma o estructura de base, la identificación de algunas fibras durante la intervención demuestra el empleo de papel amate, si bien no se puede descartar el uso de otros tipos de pliegos o incluso tejidos que, como se verá en párrafos más adelante, también se emplearon en su manufactura.

Obtenidos esos primeros volúmenes: los de parte del cuerpo y la cabeza, se procedió a su ensamblaje. Para ello se recurrió a un pequeño - pero grueso- perno de madera, cuyo corte radial y la casi ausencia de anillados sugiere su identificación con un fragmento de rama de la madera ligera de colorín (Erythrina coralloides). De esa pieza estructural, encontrada también en múltiples crucificados, tenemos también su descripción en el Cristo de Santa Teresa: "en el centro de la sagrada cabeza, se encontró un bracito de madera, de una cuarta de larga, en forma de muletilla por un extremo y roto por el otro, el cual servía, sin duda, para adaptar el cuerpo a la sagrada cabeza" (Velasco 1858: 147). En el Resucitado, dicha muletilla debió ensamblarse a la cabeza adhiriéndose a las

\footnotetext{
${ }^{7}$ Parte de esa investigación científica quedó reflejada en la publicación Araujo et al. 1989.
}

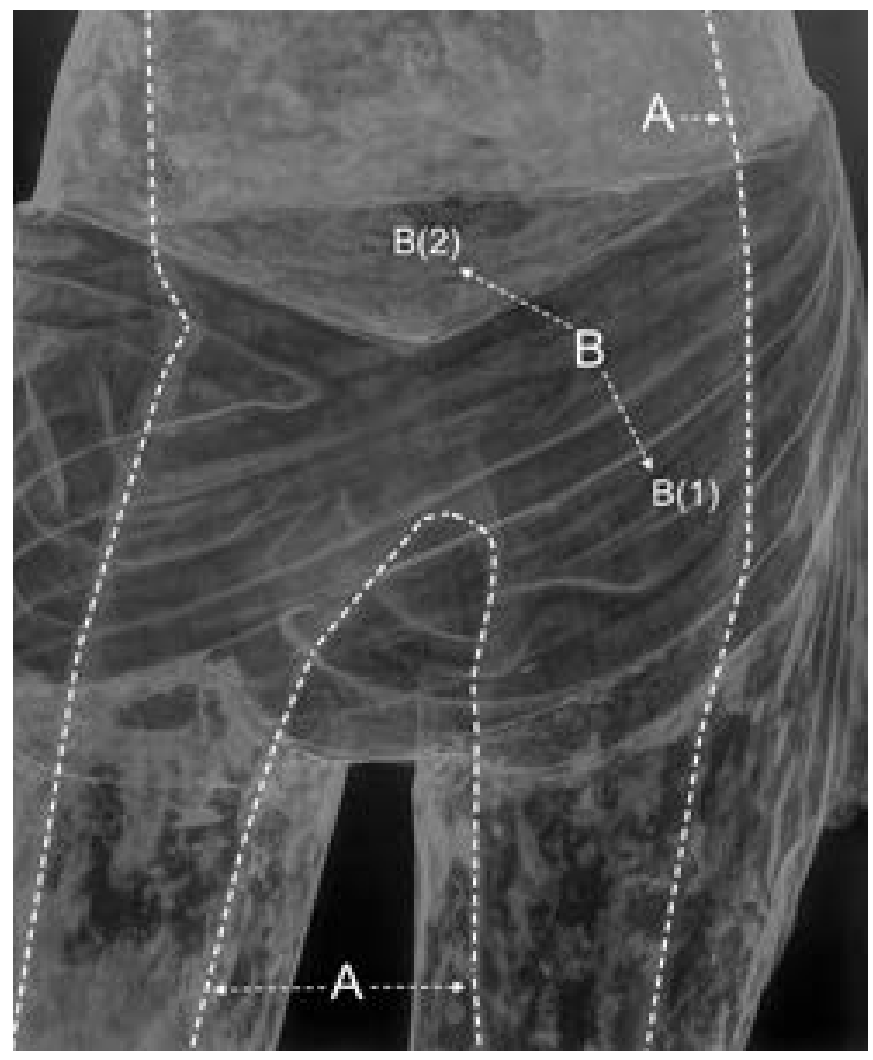

FIGURA 5. Placa de rayos X correspondiente al paño de pureza del Señor de la Ascensión de la Catedral de Tlalnepantla. El trazado de puntos (A) define la horma hueca, interior de cartón. También se observa el estofado original subyacente del paño de pureza bajo los repintes (B) (Fotografía: Pablo F. Amador Marrero, 2016).

partes correspondientes al cuello, obtenidas en las mismas matrices de papelón, para luego introducirse en el torso por medio de un corte en la horma, cuyas pestañas de papel fueron igualmente usadas para ayudar en la fijación y refuerzo del ensamble.

La indicada correspondencia entre la manera de iniciar el trabajo en las esculturas del Taller de Cortés — también compartida con otros obradores relacionados con el centro de México- genera directamente una cuestión en relación con los formatos, ya que son evidentes las sustanciales diferencias entre los múltiples crucificados vinculados con ese obrador, más de una decena (Amador 2012: 226-258) respecto de la efigie del Señor de la Ascensión: éste es ostensiblemente menor, lo que, en consecuencia, también repercute en el tamaño de su horma. Al respecto, teniendo en cuenta que los moldes estaban concebidos para su continuo uso, propongo ahora que éste también pudo usarse en la ejecución a los crucificados, las piezas con mayor demanda. Para sostener tal hipótesis me baso en el hecho de encontrar esa iconografía, pero en menor formato, vinculada directamente, por su trazado general y detalles, con el Taller de Cortés, aunque con un tamaño intermedio, entre los que el Cristo de la Salud de la ciudad de Trujillo, Cáceres, España, es uno de los ejemplos más elocuentes (Amador 2012: 252) (Figura 6). 


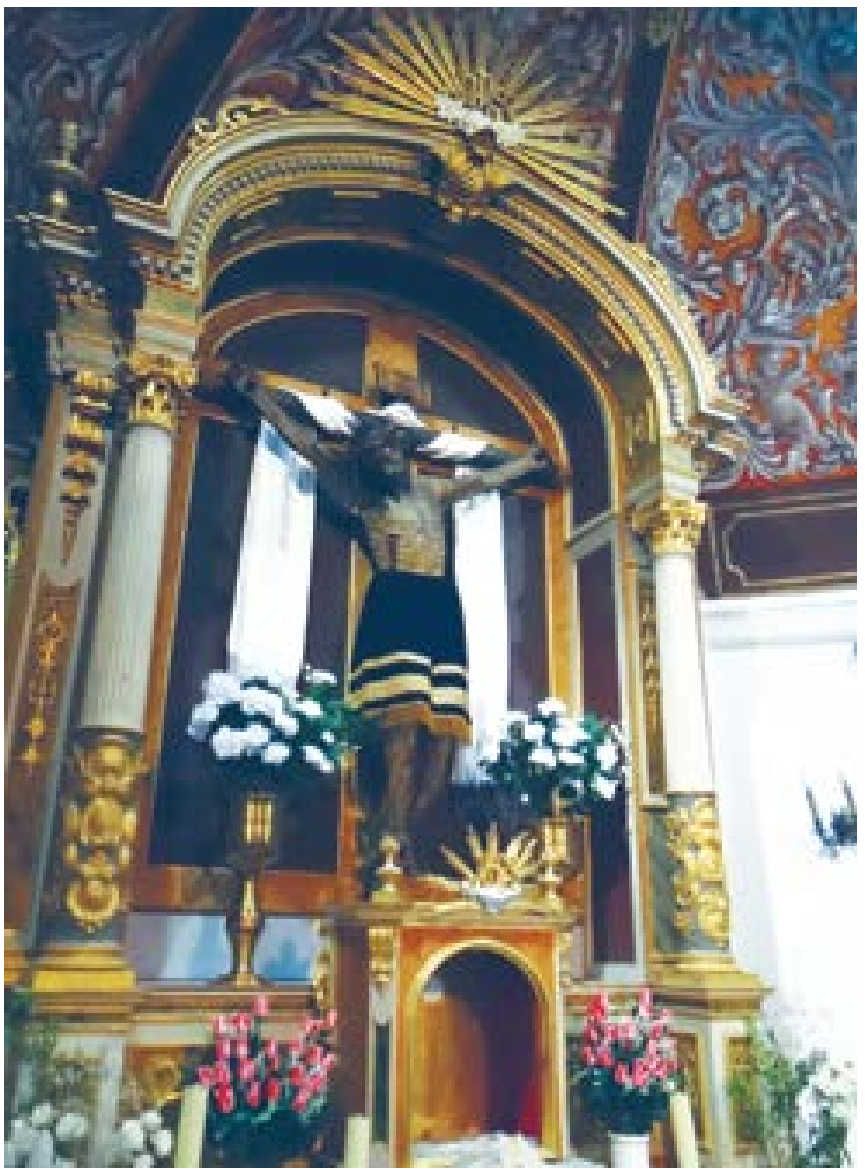

FIGURA 6. Señor de la Salud, Ermita de San Lázaro, Trujillo, España. Escultura ligera con caña de maíz, Taller de Cortés, finales del siglo XVI (Fotografía: Pablo F. Amador Marrero, 2016)

Respecto de los brazos, se ha dicho, retomando la descripción histórica, que "también están huecos, mas no se distingue en ellos la clase de horma sobre que está formado el cuerpo, sino unos simples rollos cilíndricos de capas de la materia que se describirá..." (Velasco 1858: 153), lo que se cumple, asimismo, en otros crucificados que he estudiado. Ahora bien, en la efigie de Tlalnepantla éstos varían sustancialmente, ya que están construidos mayormente con madera ligera de colorín, ${ }^{8}$ tal y como se refleja en la tomografía. El cambio tendría explicación en su adaptación iconográfica, pero también indicaría aqueIla llamada de atención que señalaba cuando lo estudié formalmente respecto de cierta dificultad en su trazado.

Concluye la estructura primigenia con la parte de las piernas y pies, que quedaron fuera en su ejecución en la matriz moldeada. Aquí el sistema —una vez más, con su correspondencia en piezas de otros crucificados- parte de sus respectivos pernos de madera ligera que se fijan al molde en una parte, y a los pies tallados en el mismo material en la otra.

\footnotetext{
${ }^{8}$ Su identificación se realizó contrastando las imágenes radiológicas obtenidas con otras que se llevaron posteriormente al estudio pormenorizado del soporte.
}

Concluida la somera forma primigenia de la imagen, el siguiente paso que se constata por la tomografía es la aplicación, en gran parte de la superficie, de un laborioso ensamble de fragmentos de cañeja (el interior de la caña del maíz, parte aérea del tallo de la planta), pero también de pasta del mismo material. La medida longitudinal de esos fragmentos quedó lógicamente condicionada tanto por la sección de los nudos que forma el tallo, como por la eliminación de algunas partes no aptas para su empleo escultórico. Éstas se dispusieron de manera ordenada, alternando sus alturas, suponemos que para no dejar líneas que pudieran ser puntos de debilidad en la estructura, lo que en paralelo nos habla de la experiencia y saber de sus artífices. A su vez, comprobé que, según la zona a trabajar, en la mayoría de las obras, como en el caso que nos ocupa, es factible discernir cómo la primera línea de cañejas, la más próxima al alma, no requirieron ser talladas, lo que se distingue por su perímetro circular, y señalan que se añadían tal como eran obtenidas al retirarles la corteza dura del tallo, correspondiendo además con las más gruesas. Para el encolado se ha podido establecer, una vez más, que se utilizó cola de origen animal, la misma que tradicionalmente se empleaba en imaginería lignaria, con lo que no se identificó el conocido adhesivo obtenido de los bulbos de la orquídea, el tatzingueni, que se asocia con la técnica de escultura con caña utilizada en piezas michoacanas, mas no del centro de México.

Según se avanzó en la colocación de la cañeja, se intuye la suma de algunos de estos fragmentos que parecieran estar tallados de manera sumaria para ir adaptándose según los espacios dejados por los estratos anteriores. Es ahí donde la anatomía se debió trabajar de modo más cuidadoso, usando elementos tanto de corte como de lijado - entre los que no se descartan limatones-, pero también algún tipo de piedra porosa. Concluido el trabajo de tallado, de sustracción, se pasó al de añadido, modelado con el empleo de pasta de serrín de la propia cañeja aglutinada con cola. Hasta este punto he mantenido la tipificación de la cañeja del maíz, basándome tanto en las imágenes de la tomografía y la propia ligereza de la obra como en mi experiencia y un fragmento mínimo de muestra, si bien la cantidad obtenida no es la suficiente para su confirmación científica. De ese punto de su fábrica tengo la evidencia material que viene a corroborar su identificación, lo que se confirmó nuevamente durante los procesos de restauración. En efecto, como manifiesta el estudio del soporte obtenido junto a una pérdida en el cabello, se logra identificar un tejido parenquimatoso en el que quedaron embebidos algunos haces vasculares, que tienen correspondencia con la conformación típica del tejido de una caña (gramínea). ${ }^{9}$ Con este estrato se homogeneizó

\footnotetext{
${ }^{9} \mathrm{Al}$ respecto he de precisar que, debido tanto a la escasa cantidad de material de la muestra en estudio como a su molienda, se limitó la observación de los componentes celulares, por lo que no fue posible definir con precisión el tipo de planta. Le agradezco a la bióloga Ana
} 
la superficie, logrando una mejor definición de los volúmenes, lo que de nuevo tiene correspondencia con la bibliografía asociada: "Sobre dicha horma y rollos está formada la parte muscular del cuerpo, con cañas de maíz del país o de otras enteramente iguales, unidas entre sí con una pasta formada también de las mismas cañas pulverizadas, la cual cubre todos los huecos que hay entre unas y otras. De esa misma pasta están trabajadas algunas partes de la cabeza, como el pelo, las orejas, barba, \&c., encontrándose siempre la caña en las partes muy abultadas" (Velasco 1858: 154).

Antes de dar paso a las fases policromas, y para concluir con el soporte - al igual que en otros casos del mismo obrador, pero también habitual de su centro productor-, se recubrió gran parte de la imagen con uno o dos tejidos, según la zona. En el caso del hombro izquierdo, debido al notable deterioro que presentaba se constató la utilización, primero, de un tejido grueso con ligamento de tafetán encolado a modo de efectivo refuerzo en la unión de piezas, al que luego se le añadió otro más fino y de igual manufactura que, si bien no se le sobrepone completamente, sí llega a solaparse en las partes inferiores para luego discurrir por el torso y brazo. Respecto de su identificación, por lo menos en uno de los casos el análisis de la sección transversal de algunas de sus fibras deja ver formas pentagonales y hexagonales irregulares, además de la identificación de laterales poligonales redondeados, lo cual condujo a su identificación como lino. Ese entelado, que para otras piezas similares cercanas se ha identificado como "una ligera capa de las mismas que hacen la horma, pero tan fina y delgada, que á pesar de su colorido, no es más gruesa que el papel común" (Velasco 1858: 154), se aplicó con la finalidad de homogeneizar la superficie y prepararla para el policromado, ayudando también en cierto modo en el moldeado anatómico (Figura 7).

Llegado a este punto, transcurrido el tiempo necesario para el fraguado de los adhesivos y, con ello, la evaporación de la mayor parte de la notable cantidad de humedad derivada del sistema constructivo, se dio paso a las fases ocultas del proceso policromo. Siguiendo la tradición española, esa parte del trabajo se inició con la aplicación de los aparejos que, según la zona, varían su grosor notablemente, lo que indica que también se usaron para ajustar el acabado anatómico. Ese estrato se compone de dos capas, ambas aglutinadas en cola; la primera llega hasta $450 \mu \mathrm{m}$ y está constituida por sulfato de calcio, yeso $\left(\mathrm{CaSO}_{4}\right)$, en el que se detecta la presencia de aluminosilicatos. De color blanco amarillento, por la dispar molienda de la carga y el grosor de muchas de sus partículas, esa

Laura Avelar Carmona su colaboración en la identificación de esos materiales; también al físico Víctor Santos (Laboratorio de Diagnóstico de Obras de Arte [LDOA], Instituto de Investigaciones Estéticas [IIE], Universidad Nacional Autónoma de México [UNAM]) su fundamental apoyo en el tratamiento y procesado de la muestras.

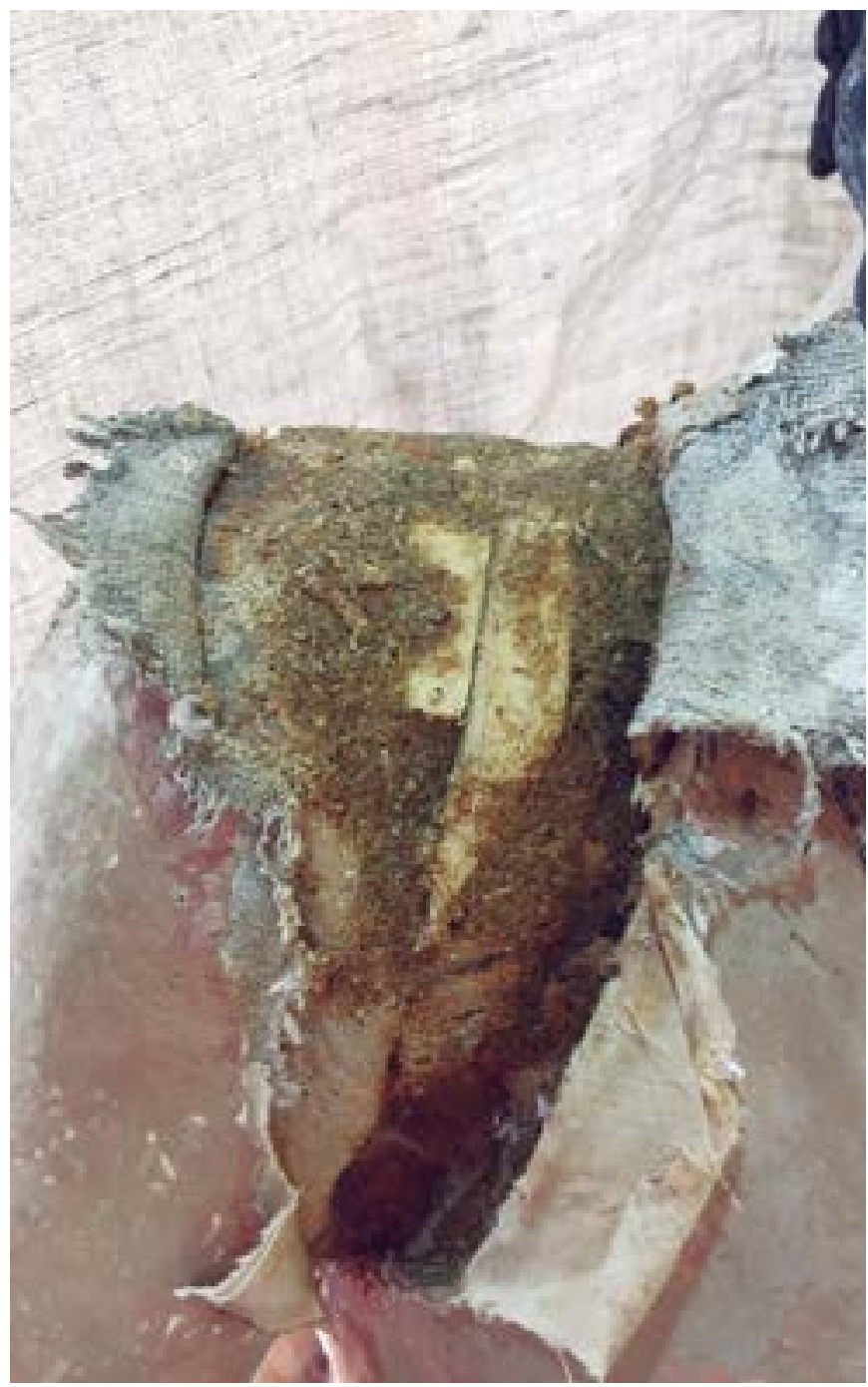

FIGURA 7. Identificación de entelados sobre el soporte en el Señor de la Ascensión visibles gracias al proceso de restauración (Fotografía: Claudia Alejandra Garza Villegas, 2016)

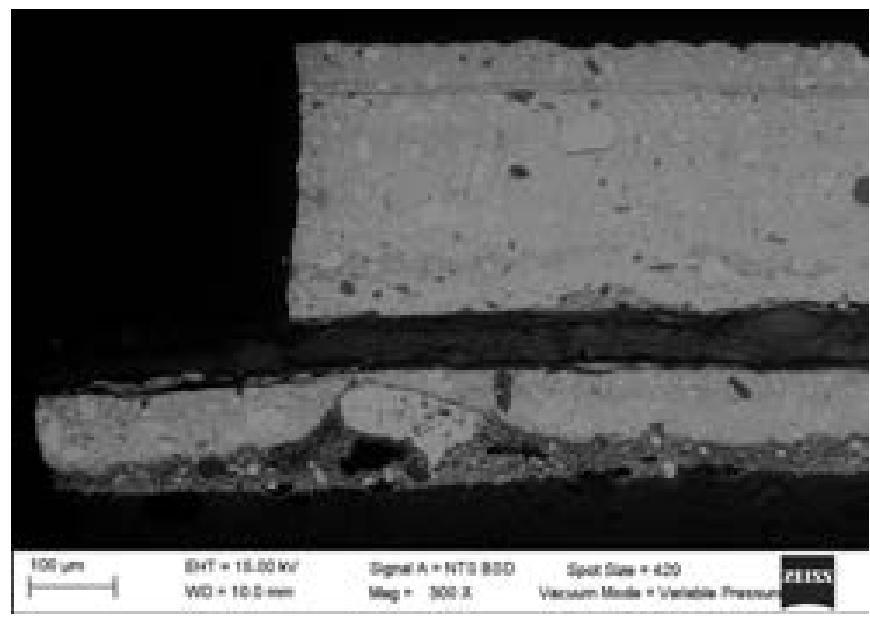

FIGURA 8. Corte estratigráfico en el que se observa la superposición de los estratos correspondientes a la policromía original y los diferentes añadidos (Fotografía: Víctor Santos; cortesía: Laboratorio de Diagnóstico de Obras de Arte [LDOA], Instituto de Investigaciones Estéticas [IIE], Universidad Nacional Autónoma de México [UNAM]). 
capa viene a corresponder con el yeso grueso. Le sigue otra de igual constitución pero más delgada, yeso fino, con una media de $86 \mu \mathrm{m}$ y un color mucho más blanco, donde la línea de conclusión es más definida, lo que señala la búsqueda de una superficie más apta para el color. Aquí el yeso tiene una molienda fina y homogénea, en al que se ha identificado un porcentaje de óxido de silicio como parte de su carga (Figura 8).

Sumamente interesante es la presencia, sobre el aparejo, de una imprimación naranja cuyo cromatismo se vuelve intenso en partes. Constituida por blanco de plomo, albayalde y minio del mismo componente —rojo de Saturno; hasta donde sabemos, su identificación no ha sido documentada en piezas ligeras novohispanas del siglo XVI. Su empleo es reportado en la edición de 1649 de Pacheco (1990: 481), es conocido para la escultura europea de aquel siglo, pero también en imaginería virreinal posterior. Ésta cumple con la finalidad de incidir directamente en la percepción de los estratos posteriores. Respecto de los últimos, en esencia es una capa constituida por matriz blanca de carbonato básico de plomo (albayalde), con la adición de algunos pigmentos que le confieren la tonalidad trigueña que hoy se percibe (Figura 9).

En cuanto a la ejecución policroma del paño de pureza, parte de la indicada base de preparación de yeso con algo de óxido de Silicio $\left(\mathrm{SiO}_{2}\right)$ y cuidada molienda, a la que se sobrepuso el tradicional estrato arcilloso de bol constituido esencialmente por óxido de hierro $\left(\mathrm{Fe}_{2} \mathrm{O}_{3}\right)$ con un espesor que oscila entre 21 y $30 \mu \mathrm{m}$. Trabajada la superficie, se le adhirió la lámina dorada, extremadamente fina, de apenas algunas micras, que corresponde con una aleación de oro $(\mathrm{Au})$ y plata $(\mathrm{Ag})$, con más de $90 \%$ del primero, lo habitual en las piezas del siglo XVI. Finalmente, tras el esmerado bruñido del metal, recibió una espesa capa del adelantado temple blanco, que fue rajado (esgrafiado) formando el trabajo ya descrito a base de franjas (Figura 10).

\section{A modo de reflexión final}

Con esta primera y variada aproximación al Señor de la Ascensión de la Catedral de Tlalnepantla, además de reclamar para él un lugar en la historia de la escultura novohispana, lo que había velado hasta el momento - aquí concluyo- es la indiscutible importancia que tiene la efectiva conjunción de las principales disciplinas involucradas: restauración, historia del arte y diferentes ciencias, para que piezas como la que traté den ese paso. Consciente del empeño que se pone en las aulas por hacer entender que las intervenciones razonadas van más allá de la recuperación en sí de la obra, insistí críticamente en que, en infinidad de ocasiones, esas mismas pautas parecen olvidarse al momento de dejar el ámbito de la formación.

Atender las múltiples posibilidades que ofrecen las intervenciones de nuestro patrimonio, y generar su

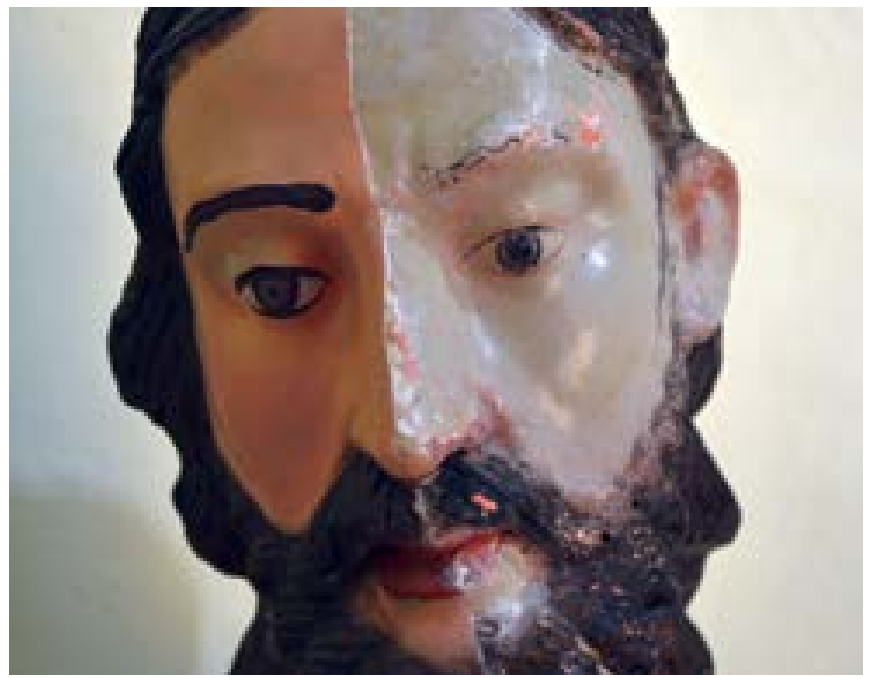

FIGURA 9. Eliminación de los repintes de las carnaciones en el que se dejan ver parte de la policromía original y elementos característicos en las formas del Taller de Cortés (Fotografía: Claudia Alejandra Garza Villegas, 2016).

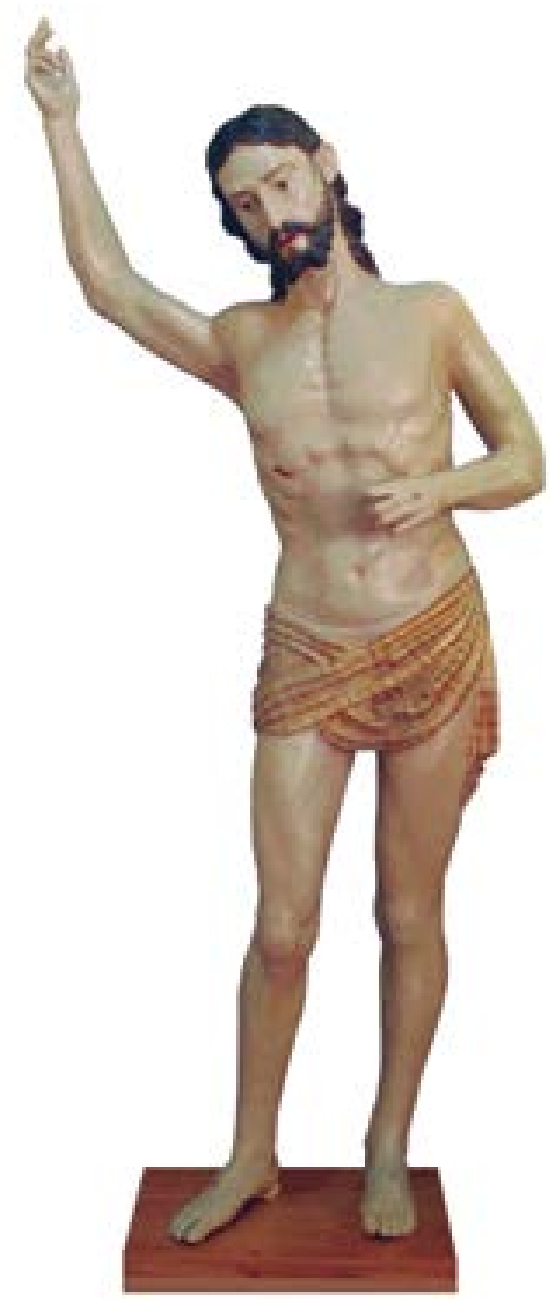

FIGURA 10. Señor de la Ascensión (Cristo Resucitado) después de la restauración, Catedral de Tlalnepantla. Escultura ligera con caña de maíz, Taller de Cortés, finales del siglo XVI (Fotografía: Claudia Alejandra Garza Villegas, 2016). 
investigación asociada, no sólo debe recaer en casos puntuales, como viene ocurriendo y es fácilmente contrastable: la lamentable evidencia de que no se le dé lugar a los historiadores del arte en los proyectos de intervención - véase, por ejemplo, su notoria ausencia en el famoso formato de trámite INAH 06-001-, no sólo mantiene la actual brecha entre las disciplinas involucradas, sino que va en detrimento de lo que prevalece internacionalmente en las mismas circunstancias. Esa conjunción, restauradorhistoriador del arte, es una imperiosa necesidad que hoy nos sigue demandando nuestro patrimonio y que, de no solucionarse, mañana nos lo reclamará la historia.

\section{Referencias}

Amador Marrero, Pablo Francisco

2002 Traza española, ropaje indiano. El Cristo de Telde y la escultura en caña de maíz, Gran Canaria, Ayuntamiento de Telde.

2012 "Imaginería ligera novohispana en el arte español de los siglos XVI-XVII", tesis de doctorado en historia del arte, Gran Canaria, Departamento de Filología Moderna, Universidad de Las Palmas de Gran Canaria.

Araujo Suárez, Rolando, Alejandro Huerta Carrillo y Sergio Guerrero Bolán

1989 Esculturas en papel amate y caña de maíz, Cuadernos Técnicos, 1, México, Museo Franz Mayer.

Archivo Histórico de la Catedral de Tlalnepantla

1786 Serie Inventarios, caja 120, leg. 1, sección Disciplinar, p.11.

Ávila Figueroa, Elizabeth

2010-2011 "Materiales y técnicas de la escultura ligera novohispana con caña de maíz: una aproximación historiográfica", tesis de maestría en historia del arte, México, Universidad Nacional Autónoma de México.

Brandi, Cesare

1995 Teoría de la restauración, Madrid, Alianza Forma.

Brito Benítez, Eva Leticia

2014 "Symbolism and use of maize in Pre-Hispanic and Colonial religious imagery in Mexico", E-conservation Journal 2: 116-127.

Dubois López, Elsa

2001 "El Cristo de Cortés de Tlaxcala, México. Estudios y conservación de una imagen en caña de maíz", en Antonio F. García-Abásolo et al. (eds.), Imaginería indígena mexicana. Una catequesis en caña de maíz, Córdoba, Publicaciones de la Obra Social y Cultural de Caja Sur, pp. 205-215.
Pacheco, Francisco

1991 [1649] El arte de la pintura, ed., introd. y notas de Buenaventura Bassegoda i Hugas, Madrid, Cátedra (Arte, Grandes temas).

Quintero Balbás, Diego Iván

2013 "Contribución al conocimiento de la técnica de manufactura de la escultura ligera", tesis de licenciatura en restauración, México, Escuela de Conservación y Restauración de Occidente.

Roda Peña, José

2016 "La cofradía del Dulce Nombre de Jesús en Sevilla y su patrimonio escultórico a finales del siglo XVI", en XVII Simposio sobre Hermandades de Sevilla y su Provincia, Sevilla, Fundación Cruzcampo, pp. 241-264.

Valverde Larrosa, Consuelo, y Juan Carlos Martín García 2017 "Intervenciones en escultura ligera en el Centro de Conservación y Restauración de Bienes Culturales de Castilla y León. Estudio y restauración del Crucificado de la Colegiata de Lerma (Burgos) y del Cristo del Consuelo (Segovia)", en Rosa María Román Garrido (ed.), Escultura ligera, Valencia, Ajuntament de València, Regidoira de Patrimoni Cultural i Recursos Culturals, pp. 72-78.

Velasco, Alonso Alberto de

1858 Historia de la milagrosa renovación de la soberana imagen de Cristo Señor Nuestro Crucificado, que se venera en la iglesia del convento de Santa Teresa la Antigua, México, Imprenta de Andrade y Escalante.

\section{Síntesis curricular del/los autor/es}

\section{Pablo F. Amador Marrero}

Investigador del Instituto de Investigaciones Estéticas (IIE),

Universidad Nacional Autónoma de México (UNAM), México agueretf@hotmail.com

Investigador del Instituto de Investigaciones Estéticas (IIE), de la Universidad Nacional Autónoma de México (UNAM), rama de Estudios de Arte Virreinal. Es licenciado en Bellas Artes (Universidad de Granada [UGR], España) con especialidad de restauración escultórica, maestro en historia del arte (Universidad de La Laguna [ULL], España) y doctor en historia del arte (Universidad de Las Palmas de Gran Canaria [ULPGC], España). Profesor de maestría y doctorado en historia del arte de la UNAM y de licenciatura en la UABJO (Universidad Autónoma Benito Juárez de Oaxaca, México). Es autor de diversos libros y artículos, así como restaurador de un considerable número de obras flamencas, italianas, españolas y americanas. 